H. K. Åkerblom · S. M. Virtanen - J. Ilonen •

E. Savilahti - O. Vaarala $\cdot$ A. Reunanen $\cdot$ K. Teramo ·

A.-M. Hämäläinen · J. Paronen · National TRIGR

Study Groups

\title{
Dietary manipulation of beta cell autoimmunity in infants at increased risk of type 1 diabetes: a pilot study
}

Received: 28 September 2004 / Accepted: 15 January 2005 / Published online: 19 April 2005

(C) Springer-Verlag 2005

\begin{abstract}
Aims/hypothesis: We aimed to assess the feasibility of a dietary intervention trial with weaning to hydrolysed formula in infants at increased risk of type 1 diabetes and to study the effect of the intervention on the emergence of diabetes-associated autoantibodies in early childhood. Methods: We studied 242 newborn infants who had a first-degree relative with type 1 diabetes and carried risk-associated $H L A-D Q B 1$ alleles. After exclusive breastfeeding, the infants underwent a double-blind, randomised pilot trial of either casein hydrolysate (Nutramigen; Mead
\end{abstract}

Presented in part at the 59th Annual Meeting of the American Diabetes Association (ADA) in San Diego, June 1999, and at the 61st Annual Meeting of ADA, President's Session on Late-Breaking Abstracts, June 2001, Philadelphia

H. K. Åkerblom $(\bowtie) \cdot$ E. Savilahti · O. Vaarala · J. Paronen Hospital for Children and Adolescents,

Biomedicum Helsinki, University of Helsinki,

(Haartmaninkatu 8),

PO Box 700, 00029 Helsinki, Finland

e-mail: hans.akerblom@helsinki.fi

Tel.: +358-9-47171938

Fax: +358-9-19125229

\section{S. M. Virtanen}

Tampere School of Public Health,

University of Tampere,

Tampere, Finland

S. M. Virtanen

Tampere University Hospital Research Unit,

Tampere, Finland

S. M. Virtanen

Department of Epidemiology and Health Promotion,

National Public Health Institute,

Helsinki, Finland

J. Ilonen

Department of Virology, University of Turku,

Turku, Finland

\section{O. Vaarala}

Clinical Research Centre, Faculty of Health Sciences,

Linköping University,

Linköping, Sweden
Johnson) or conventional cow's milk-based formula until the age of 6-8 months. During a mean observation period of 4.7 years, autoantibodies to insulin, anti-glutamic acid decarboxylase and insulinoma-associated antigen- 2 were measured by radiobinding assays, and islet cell antibodies (ICA) by immunofluorescence. Results: The feasibility of screening and identifying a cohort of first-degree relatives with $H L A$-conferred disease susceptibility, enrolling them in a dietary intervention trial and following them for seroconversion to autoantibody positivity is established. The

\section{A. Reunanen}

Department of Health and Functional Capacity,

National Public Health Institute,

Helsinki, Finland

K. Teramo

Department of Obstetrics and Gynaecology,

University of Helsinki,

Helsinki, Finland

A.-M. Hämäläinen

Department of Paediatrics,

University of Oulu,

Oulu, Finland

M.-A. Riikjärv

Tallin Children's Hospital, Tallinn,

Estonia

A. Ormisson

Department of Paediatrics,

University of Tartu,

Tartu, Estonia

J. Ludvigsson

Department of Paediatrics,

Department of Health and Environment,

Faculty of Health Sciences,

Linkoping University,

Linkoping University,

Linkoping, Sweden 
cumulative incidence of autoantibodies was somewhat smaller in the casein hydrolysate vs control formula group, suggesting the need for a larger well-powered study. After adjustment for duration of study formula feeding, life-table analysis showed a significant protection by the intervention from positivity for ICA $(p=0.02)$ and at least one autoantibody ( $p=0.03)$. Conclusions/interpretation: The present study provides the first evidence ever in man, despite its limited power, that it may be possible to manipulate spontaneous beta cell autoimmunity by dietary intervention in infancy.

Keywords Beta cell autoimmunity · Dietary manipulation · Feasibility - Infants - Type 1 diabetes

Abbreviations BB: BioBreeding - CM: cow's milk . FDR: first-degree relative - GADA: anti-glutamic acid decarboxylase antibodies - IA-2A: anti-insulinomaassociated antigen-2 antibodies - IAA: insulin autoantibodies - ICA: islet-cell antibodies - NOD: nonobese diabetic . TRIGR: Trial to Reduce IDDM in the Genetically at Risk

\section{Introduction}

The possible role of complex foreign-protein weaning diets, such as cow's milk (CM)-based formulas, in the aetiology and pathogenesis of type 1 diabetes has long been debated. A series of epidemiological and immunological studies suggests that exposure to these proteins in early infancy may increase the risk of type 1 diabetes in genetically susceptible individuals. However, findings refuting this hypothesis have also been reported (reviewed in [1-3]). While most of the surveys on breastfeeding and weaning diets have been retrospective, prospective studies have been initiated, but their results have also been inconsistent, e.g. $[4,5]$.

The trial to reduce IDDM in the genetically at risk (TRIGR) project was launched to address the role of complex foreign protein-weaning diets in the natural history of type 1 diabetes [6]. We report here salient findings from the second pilot study of the TRIGR project, carried out in Finland, Estonia and Sweden with the primary aims of (1) developing and testing protocols for a nutritional intervention trial in infants with increased genetic diabetes risk, and (2) assessing the feasibility of such an approach, and secondarily of determining whether delayed exposure to a complex weaning diet, such as a CM-based formula, decreases the emergence of autoantibodies associated with the risk of diabetes in early childhood.

\section{Subjects and methods}

\section{Subjects}

Recruitment and follow-up This multicentre study involved 15 hospitals in Finland, two in Estonia and one in Sweden.
Newborn infants with a first-degree relative (FDR) affected by type 1 diabetes were recruited between April 1995 and May 1999. Written informed consent was obtained from the family before enrolment. The study was approved by the Joint Ethics Committees of the participating hospitals. During a period of 2 years and 8 months, 521 newborn infants were identified in Finland for the study. Forty-five did not fulfil the inclusion criteria, mainly due to prematurity (gestational age $<36$ weeks) or unavailability of a cord blood sample for HLA genotyping. Altogether, 476 newborn infants received a study code at birth, and 471 were genetically screened. The results of the HLA genotyping were usually obtained within 1 week. In Finland, 230 newborn infants with an eligible $H L A$-risk genotype continued in the intervention study. The corresponding figures for Estonia were 21 genetically screened, eight eligible to continue, and for Sweden eight genetically screened, four continuing based on their HLA constellation, resulting in a total series of 242 subjects. Thirty-eight per cent of infants had a mother with type 1 diabetes, $43 \%$ an affected father, $15 \%$ had an affected sibling and $4 \%$ had more than one affected FDR.

The study was initially approved (Finland, Estonia, Sweden) for observation of children up to the age of 2 years. In Finland, we were able to obtain data also from follow-up visits at the age of 3, 5 and 7 years. At the followup visits, blood was drawn after application of an analgesic cream at 3, 6, 9, 12, 18 and 24 months of age, and in Finnish children in addition at 3,5 and 7 years of age. Serum specimens were stored at $-70^{\circ} \mathrm{C}$ until analysed. Autoantibody data were obtained from 220 children who had at least one follow-up sample available, 208 of them being Finnish. The mean follow-up time for autoantibodies in the latter was 4.7 years (range 3 months to 8 years).

Findings related to feasibility and manifest diabetes are presented for all subjects, whereas autoantibody results are only from the Finnish children, due to their considerably longer follow-up time compared with that in Estonian and Swedish subjects.

Randomisation Breastfeeding was encouraged and exceeded national averages in both intervention arms. Infants were randomised after birth to receive, whenever breast milk was not available, either the intervention formula (Nutramigen, based on extensively hydrolysed casein) or the control whey-enriched CM protein formula, both provided by Mead Johnson Nutritionals, Evansville, IL, USA. The control formula included $20 \%$ Nutramigen to mask taste and smell differences between the two study formulas. Study formulas were prepared and colour-coded in four sets by the company, which kept the codes. Newborn infants requiring supplemental feeding prior to randomisation (e.g. subjects born at night or on weekends) received banked breast milk or casein hydrolysate formula. The codes were opened when the last child had completed the dietary intervention period. One hundred and twenty-two subjects were randomised to the casein hydrolysate group and 120 subjects to the control group. 
Dietary intervention The breastfeeding practices were entirely at the discretion of the participating mothers and the diet of the mothers was not modified. The dietary intervention period lasted until the infant was at least 6 months of age. If the mother chose to exclusively breastfeed up to the age of 6 months, a further opportunity to use the study formula was provided for up to 2 months or until reaching the age of 8 months. All infant food products containing $\mathrm{CM}$ or beef were excluded in the diet of the infants during the intervention period. Compliance was monitored by regular family interviews.

The casein hydrolysate formula has been shown to reduce diabetes frequency in the nonobese diabetic (NOD) mouse [7] and BioBreeding (BB) rat [8] models, and to be less immunogenic than the conventional CM-based formula in infants [9].

\section{Methods}

$H L A$ genotyping Cord blood $H L A-D Q B 1$ genotype analysis was done at the Department of Virology, University of Turku, Turku, Finland to define selected alleles $\left(D Q B 1^{*} 02\right.$, $* 0301, * 0302$ and *0602/3) known to be significantly associated with either susceptibility to or protection against type 1 diabetes [10]. The technique is based on solution hybridisation with lanthanide-labelled oligonucleotide probes detected with time-resolved fluorometry, and is suitable for screening of a large number of samples [11]. Children with the $H L A-D Q B 1^{*} 02$ and/or $D Q B 1^{*} 0302$ allele without protective alleles $(D Q B 1 * 0301, * 0602$ and $* 0603)$ were recruited for the study. The $H L A-D Q B 1 * 02 / * 0302$ genotype was found in $22 \%$ of the subjects in the CM-based formula group and in $21 \%$ of the children in the casein hydrolysate group, and the respective proportions were 39 and $41 \%$ for $D Q B 1 * 0302 / x(x \# D Q B 1 * 02, * 0301, * 0602$, $* 0603)$ and 39 and $38 \%$ for the $D Q B 1 * 02 / y(y \# D Q B 1 * 0301$, $* 0302, * 0602, * 0603)$ genotype.

Islet-cell-related autoimmune markers Islet-cell-related autoimmune markers were analysed blindly in the Research Laboratory, Department of Paediatrics, University of Oulu, Oulu, Finland. The assays of islet-cell antibodies (ICA), insulin autoantibodies (IAA), anti-glutamic acid decarboxylase antibodies (GADA) and anti-insulinoma-associated antigen-2 antibodies (IA-2A) are described in detail in a recent paper by Kukko et al. [12]. The disease sensitivity of the ICA assay was $100 \%$ and the specificity $98 \%$ in the Fourth Immunology and Diabetes Workshop for the Standardisation of Cytoplasmic ICA [13]. The disease sensitivity of the IAA assay was $44 \%$ and the specificity $98 \%$ in the 2002 Diabetes Autoantibody Standardisation Programme (DASP) Workshop. The same characteristics of the GADA assay were 82 and $98 \%$ and those of the IA-2A assay 62 and $100 \%$, respectively. The samples from each individual were analysed in the same assay to eliminate interassay variation. Samples with IAA, GADA or IA-2A levels between the 95th and 99.5th percentiles were reanalysed for confirma- tion. Transplacentally transferred maternal antibodies were disregarded in the analysis.

Progression to type 1 diabetes Although testing the effect of intervention on the development of type 1 diabetes was not the primary aim of this feasibility study, progression to diabetes was registered. The information was primarily derived from data obtained from paediatric clinics taking care of the children, and information obtained during scheduled follow-up visits. In addition, the diabetes incidence in the entire intervention and control groups was drawn from a national drug reimbursement register with essentially complete population coverage as a secondary source [14].

Statistical methods The difference in the duration of exposure to study formula feeding between the two groups was compared by the Mann-Whitney $U$-test. In order to account for the interval-censoring caused by the discrete time points of measurements, the hazard ratios of seroconversion to positivity for diabetes-predictive autoantibodies that occurred during the follow-up and were associated with the infant formula feeding were estimated by life-table survival regression [15]. An adjustment in the analysis was made for the duration of the exposure for study formula feeding by treating it as a binary variable with a cut point at 3 months ( $<3$, equal or $>3$ months). The 'intention to treat' principle was applied in analysing seroconversion to autoantibody positivity and progression to type 1 diabetes. All tests were two-tailed with the level of significance set at $5 \%$. With a sample size of about 100 subjects on each of the treatment arms, and a median follow-up of nearly 5 years, the study has limited statistical power to detect reductions in the observed incidence in seroconversion and in the observed incidence of diabetes. Hence, the results reported here are considered to be those of a pilot study where feasibility and trends are the primary outcomes of interest. A $p$ value of less than 0.05 was considered statistically significant.

\section{Results}

Feasibility One hundred and ninety-one subjects (78\%) remained in the study for the first 2 years, which was the initial end point. The Finnish children were subsequently invited for further follow-up, and 171 participants (74\%) attended the 3-year visit and $143(62 \%)$ the 5-year visit, while 72 children $(31 \%)$ had come for the 7 -year visit by the end of August 2003. The proportions of children attending the 3-, 5- and 7-year visits were very similar in the two formula groups. A considerable proportion of the drop-outs over the first 2 years (22 out of 55) occurred before the age of 3 months, various family problems being the most common reason. The duration of study formula feeding was as follows: none at all, $12.4 \%$ in the casein hydrolysate group and $9.8 \%$ in the control group; less than 2 months, 4.1 and $6.9 \%$; from 2 to 6 months, 66 and $62.7 \%$; more than 6 months, 17.5 and $20.6 \%$, respectively. 
Table 1 Emergence of autoantibodies over the first 5-7 years of life in infants taking part in the second pilot of TRIGR

\begin{tabular}{|c|c|c|c|c|c|c|c|c|c|c|c|c|c|c|c|}
\hline \multirow{2}{*}{$\begin{array}{l}\text { Feed } \\
\text { formula/case no. }\end{array}$} & \multirow[t]{2}{*}{ Sex } & \multirow[t]{2}{*}{ Genotype } & \multirow[t]{2}{*}{ Proband } & \multicolumn{11}{|c|}{ Age (months) } & \multirow{2}{*}{$\begin{array}{l}\text { Type } 1 \text { diabetes } \\
\text { diagnosis (age) }\end{array}$} \\
\hline & & & & 36 & 9 & 12 & 18 & 24 & 36 & 48 & 60 & 72 & 84 & 96 & \\
\hline \multicolumn{16}{|c|}{ Casein hydrolysate } \\
\hline \multirow[t]{4}{*}{1} & $\mathrm{M}$ & $* 0302 / x$ & Father, sibling & & & & & & & & $\mathrm{ICA}^{\mathrm{a}}$ & ICA & ICA & & \\
\hline & & & & & & & & & & & & $\mathrm{IAA}^{\mathrm{a}}$ & 0 & & \\
\hline & & & & & & & & & & & $\mathrm{GADA}^{\mathrm{a}}$ & GADA & GADA & & \\
\hline & & & & & & & & & & & $\mathrm{IA}-2 \mathrm{~A}^{\mathrm{a}}$ & IA- $2 \mathrm{~A}$ & IA-2A & & \\
\hline 2 & $\mathrm{~F}$ & $* 02 / y$ & Sibling & & & & & & & & & & $\mathrm{GADA}^{\mathrm{a}}$ & & \\
\hline \multirow[t]{4}{*}{3} & M & $*_{02} / * 0302$ & Mother, brother & & & & & & & & $\mathrm{IAA}^{\mathrm{a}}$ & IAA & $\mathrm{ICA}^{\mathrm{a}}$ & ICA & \\
\hline & & & & & & & & & & & $\mathrm{GADA}^{\mathrm{a}}$ & GADA & IAA & IAA & \\
\hline & & & & & & & & & & & & & GADA & GADA & \\
\hline & & & & & & & & & & & & & $\mathrm{IA}-2 \mathrm{~A}^{\mathrm{a}}$ & IA-2A & \\
\hline \multirow[t]{3}{*}{4} & M & $* 02 / * 0302$ & Father, sibling & & & $\mathrm{ICA}^{\mathrm{a}}$ & & & & & & & & & 06/97 (13 months) \\
\hline & & & & & & $\mathrm{IAA}^{\mathrm{a}}$ & & & & & & & & & \\
\hline & & & & & & $\mathrm{GADA}^{\mathrm{a}}$ & & & & & & & & & \\
\hline 5 & M & $* 0302 / x$ & Mother & & & & & & IAA $^{\mathrm{a}}$ & NA & 0 & & & & \\
\hline \multirow[t]{4}{*}{6} & M & $* 02 / * 0302$ & Father & & & & $\mathrm{ICA}^{\mathrm{a}}$ & ICA & ICA & ICA & ICA & ICA & & & \\
\hline & & & & & $\mathrm{IAA}^{\mathrm{a}}$ & IAA & IAA & IAA & 0 & 0 & IAA & IAA & & & \\
\hline & & & & & & & $\mathrm{GADA}^{\mathrm{a}}$ & 0 & 0 & 0 & 0 & 0 & & & \\
\hline & & & & & & & $\mathrm{IA}-2 \mathrm{~A}^{\mathrm{a}}$ & IA-2A & IA-2A & IA-2A & 0 & IA-2A & & & \\
\hline 7 & M & $* 0302 / x$ & Father & & & $\mathrm{IAA}^{\mathrm{a}}$ & 0 & 0 & 0 & 0 & 0 & & & & \\
\hline \multirow[t]{4}{*}{8} & $\mathrm{~F}$ & $* 0302 / x$ & Mother & & $\mathrm{ICA}^{\mathrm{a}}$ & ICA & ICA & ICA & ICA & ICA & ICA & & & & 11/02 (65 months) \\
\hline & & & & & & $\mathrm{IAA}^{\mathrm{a}}$ & IAA & 0 & 0 & 0 & 0 & & & & \\
\hline & & & & & $\mathrm{GADA}^{\mathrm{a}}$ & GADA & GADA & GADA & GADA & GADA & GADA & & & & \\
\hline & & & & & & & $\mathrm{IA}-2 \mathrm{~A}^{\mathrm{a}}$ & IA- $2 \mathrm{~A}$ & IA- $2 \mathrm{~A}$ & IA-2A & IA- $2 \mathrm{~A}$ & & & & \\
\hline \multirow[t]{3}{*}{9} & $\mathrm{~F}$ & $* 0302 / x$ & Father & & & & & & $\mathrm{ICA}^{\mathrm{a}}$ & ICA (DIAG) & & & & & 07/01 (48 months) \\
\hline & & & & & & & & & $\mathrm{GADA}^{\mathrm{a}}$ & GADA & & & & & \\
\hline & & & & & & & & & IA- $2 A^{a}$ & IA- $2 \mathrm{~A}$ & & & & & \\
\hline \multirow[t]{2}{*}{10} & $\mathrm{~F}$ & $* 02 / y$ & Father & & $\mathrm{ICA}^{\mathrm{a}}$ & ICA & ICA & ICA & ICA & 0 & 0 & & & & \\
\hline & & & & & & $\mathrm{GADA}^{\mathrm{a}}$ & GADA & GADA & 0 & 0 & 0 & & & & \\
\hline Control formula & & & & & & & & & & & & & & & \\
\hline 11 & M & $* 02 / * 0302$ & Mother & & & & & & & & $\mathrm{ICA}^{\mathrm{a}}$ & ICA & ICA & & \\
\hline & & & & & & & & & & & $\mathrm{GADA}^{\mathrm{a}}$ & GADA & 0 & & \\
\hline 12 & $\mathrm{~F}$ & $* 0302 / x$ & Father & $\mathrm{IAA}^{\mathrm{a}}$ & NA & NA & $\mathrm{NA}$ & & & & & & & & 07/97 (20 months) \\
\hline 13 & M & $* 02 / y$ & Mother & & & & $\mathrm{ICA}^{\mathrm{a}}$ & ICA & NA & NA & NA & & & & \\
\hline & & & & & & $\mathrm{IAA}^{\mathrm{a}}$ & IAA & IAA & NA & NA & NA & & & & \\
\hline & & & & & & & $\mathrm{GADA}^{\mathrm{a}}$ & GADA & NA & NA & NA & & & & \\
\hline & & & & & & & $\mathrm{IA}-2 \mathrm{~A}^{\mathrm{a}}$ & IA- $2 \mathrm{~A}$ & NA & NA & NA & & & & \\
\hline 14 & M & $* 02 / y$ & Mother & & & & $\mathrm{ICA}^{\mathrm{a}}$ & ICA & 0 & NA & NA & & & & \\
\hline & & & & & & & $\mathrm{IAA}^{\mathrm{a}}$ & 0 & 0 & NA & NA & & & & \\
\hline 15 & M & $* 02 / * 0302$ & Sibling & & & $\mathrm{ICA}^{\mathrm{a}}$ & ICA & ICA & ICA & ICA & & & & & 01/01 (57 months) \\
\hline & & & & & $\mathrm{IAA}^{\mathrm{a}}$ & IAA & IAA & IAA & IAA & 0 & & & & & \\
\hline & & & & & & & $\mathrm{GADA}^{\mathrm{a}}$ & GADA & GADA & GADA & & & & & \\
\hline & & & & & & & IA- $2 \mathrm{~A}^{\mathrm{a}}$ & IA- $2 \mathrm{~A}$ & IA- $2 \mathrm{~A}$ & 0 & & & & & \\
\hline 16 & M & $* 02 / y$ & Sibling & & & & & & & & $\mathrm{ICA}^{\mathrm{a}}$ & ICA & & & \\
\hline 17 & M & $* 02 / y$ & Mother & & $\mathrm{ICA}^{\mathrm{a}}$ & ICA & & & & & & & & & 06/97 (12.5 months) \\
\hline & & & & & $\mathrm{IAA}^{\mathrm{a}}$ & IAA & & & & & & & & & \\
\hline & & & & & & $\mathrm{IA}-2 \mathrm{~A}^{\mathrm{a}}$ & & & & & & & & & \\
\hline 18 & M & $* 02 / y$ & Father & & $\mathrm{ICA}^{\mathrm{a}}$ & ICA & ICA & ICA & ICA & & & & & & 06/99 (36 months) \\
\hline & & & & & $\mathrm{IAA}^{\mathrm{a}}$ & IAA & IAA & IAA & IAA & & & & & & \\
\hline & & & & & $\mathrm{GADA}^{\mathrm{a}}$ & GADA & GADA & GADA & GADA & & & & & & \\
\hline & & & & & & & $\mathrm{IA}-2 \mathrm{~A}^{\mathrm{a}}$ & IA- $2 \mathrm{~A}$ & $\mathrm{IA}-2 \mathrm{~A}$ & & & & & & \\
\hline 19 & M & $* 0302 / x$ & Father & & & & & $\mathrm{ICA}^{\mathrm{a}}$ & ICA & ICA & ICA & & & & 04/03 (68 months) \\
\hline & & & & & $\mathrm{IAA}^{\mathrm{a}}$ & IAA & IAA & IAA & IAA & IAA & IAA & & & & \\
\hline & & & & & & & & & & $\mathrm{IA}-2 \mathrm{~A}^{\mathrm{a}}$ & IA-2A & & & & \\
\hline
\end{tabular}


Table 1 (continued)

\begin{tabular}{|c|c|c|c|c|c|c|c|c|c|c|c|c|c|c|c|c|}
\hline \multirow{2}{*}{$\begin{array}{l}\text { Feed } \\
\text { formula/case no. }\end{array}$} & \multirow[t]{2}{*}{ Sex } & \multirow[t]{2}{*}{ Genotype } & \multirow[t]{2}{*}{ Proband } & \multicolumn{12}{|c|}{ Age (months) } & \multirow{2}{*}{$\begin{array}{l}\text { Type } 1 \text { diabetes } \\
\text { diagnosis (age) }\end{array}$} \\
\hline & & & & 3 & 6 & 9 & 12 & 18 & 24 & 36 & 48 & 60 & 72 & 84 & 96 & \\
\hline \multirow[t]{4}{*}{20} & $\mathrm{~F}$ & $* 02 / * 0302$ & Mother & & & & & & & & NA & $\mathrm{ICA}^{\mathrm{a}}$ & & & & 08/01 (60 months) \\
\hline & & & & & & & & & & $\mathrm{IAA}^{\mathrm{a}}$ & NA & IAA & & & & \\
\hline & & & & & & & & & & $\mathrm{GADA}^{\mathrm{a}}$ & NA & GADA & & & & \\
\hline & & & & & & & & & & & & $\mathrm{IA}-2 \mathrm{~A}^{\mathrm{a}}$ & & & & \\
\hline 21 & $\mathrm{~F}$ & $* 02 / * 0302$ & Sibling & & & & & & & & & $\mathrm{ICA}^{\mathrm{a}}$ & ICA & & & \\
\hline \multirow[t]{4}{*}{22} & M & $* 0302 / x$ & Father & & & & & $\mathrm{ICA}^{\mathrm{a}}$ & ICA & ICA & ICA & ICA & & & & 06/01 (57 months) \\
\hline & & & & & & $\mathrm{IAA}^{\mathrm{a}}$ & IAA & IAA & IAA & IAA & IAA & IAA & & & & \\
\hline & & & & & & & & & & $\mathrm{GADA}^{\mathrm{a}}$ & GADA & 0 & & & & \\
\hline & & & & & & & & & & $\mathrm{IA}-2 \mathrm{~A}^{\mathrm{a}}$ & IA-2A & IA-2A & & & & \\
\hline 23 & $\mathrm{~F}$ & $* 02 / * 0302$ & Father & & & $\mathrm{IA}-2 \mathrm{~A}^{\mathrm{a}}$ & IA-2A & 0 & 0 & 0 & NA & 0 & & & & \\
\hline 24 & M & $* 0302 / x$ & Mother & & & & & & & $\mathrm{ICA}^{\mathrm{a}}$ & NA & 0 & 0 & & & \\
\hline 25 & M & $* 0302 / x$ & Mother & & & & & & & & & $\mathrm{ICA}^{\mathrm{a}}$ & ICA & & & \\
\hline \multirow[t]{3}{*}{26} & $\mathrm{~F}$ & $* 02 / * 0302$ & Sibling & & & & & & $\mathrm{ICA}^{\mathrm{a}}$ & 0 & NA & ICA & & & & \\
\hline & & & & & & & & & & & & $\mathrm{GADA}^{\mathrm{a}}$ & & & & \\
\hline & & & & & & & & & & & & $\mathrm{IA}-2 \mathrm{~A}^{\mathrm{a}}$ & & & & \\
\hline \multirow[t]{4}{*}{27} & $\mathrm{~F}$ & $* 02 / y$ & Sibling & & & & $\mathrm{ICA}^{\mathrm{a}}$ & ICA & ICA & ICA & ICA & ICA & ICA & & & \\
\hline & & & & & & & & $\mathrm{IAA}^{\mathrm{a}}$ & IAA & IAA & IAA & 0 & 0 & & & \\
\hline & & & & & & & & & $\mathrm{GADA}^{\mathrm{a}}$ & GADA & GADA & GADA & GADA & & & \\
\hline & & & & & & & & IA $-2 A^{a}$ & IA-2A & IA-2A & IA-2A & IA-2A & IA-2A & & & \\
\hline 28 & $\mathrm{~F}$ & $* 02 / y$ & Mother & & & & $\mathrm{ICA}^{\mathrm{a}}$ & NA & NA & 0 & NA & & & & & \\
\hline \multirow[t]{3}{*}{29} & $\mathrm{~F}$ & $* 0302 / x$ & Father & & & & & & & & IAA $^{\mathrm{a}}$ (DIAG) & & & & & 09/01 (49 months) \\
\hline & & & & & & & & & & & $\mathrm{GADA}^{\mathrm{a}}$ & & & & & \\
\hline & & & & & & & & & & & $\mathrm{IA}-2 \mathrm{~A}^{\mathrm{a}}$ & & & & & \\
\hline 30 & M & $* 0302 / x$ & Father & & & & & $\mathrm{ICA}^{\mathrm{a}}$ & 0 & 0 & NA & & & & & \\
\hline 31 & M & $* 0302 / x$ & Father & & & & & $\mathrm{ICA}^{\mathrm{a}}$ & ICA & ICA & ICA & 0 & & & & \\
\hline
\end{tabular}

Table lists only cases where autoantibodies were detected before or at the latest at the time of diagnosis

GADA Anti-glutamic acid decarboxylase antibodies, $I A-2 A$ anti-insulinoma-associated antigen-2 antibodies, $I A A$ insulin autoantibodies, $I C A$ islet-cell antibodies, $N A$ sample not available, TRIGR trial to reduce IDDM in the genetically at risk

${ }^{\text {a }}$ First appearance of a specific autoantibody

Growth Height and weight rates were identical in the two groups.

Beta cell autoimmunity: emergence of autoantibodies Individual data on sex, genotype and autoantibody appearance in the children are presented in Table 1. IAA were the first antibodies to appear, in one subject by 6 months of age and in six infants at 9 months of age. IAA were followed by ICA, five subjects testing positive at 9 months of age. The appearance of ICA, IAA, IA-2A, at least one autoantibody and at least two autoantibodies by age in the casein hydrolysate (hydrolysed formula) group and in the control group (conventional CM-based formula) among the Finnish study subjects are presented as Kaplan-Meier plots in Fig. 1a-e. At the end of the follow-up, $9.5 \%$ of the subjects in the hydrolysate group tested positive for ICA and about $20 \%$ of the control subjects $(p=0.022)$ (Fig. 1a), whereas for IAA and IA-2A, the differences were not significant (Fig. 1b, c). At the end of the observation period, $13 \%$ of the subjects in the hydrolysate group had positivity for at least one autoantibody vs $22 \%$ in the control subjects $(p=0.032)$ (Fig. 1d).

The outcome of the life-table survival analysis for Finnish subjects is shown in Table 2. The unadjusted hazard ratio for seroconversion to positivity for ICA was lower in the casein hydrolysate group $(p=0.033)$, and the hazard ratio for seroconversion to positivity for at least one autoantibody tended to be smaller in that group $(p=0.061)$. There was a difference between the two intervention groups in the duration of study formula exposure (median duration 3.1 months in the casein hydrolysate vs 4.9 months in the control group, $p=0.019)$. Therefore, the analyses were adjusted for the duration of study formula feeding. After the adjustment, a significant protective effect of the intervention was observed in relation to positivity for ICA $(p=0.022)$ and for at least one autoantibody $(p=0.032)$, and for IA-2A positivity, there was a non-significant trend in the same direction $(p=0.07)$. There were no observed differences in the hazard ratios for the other autoantibodies or the appearance of multiple antibodies in either the unadjusted or adjusted analyses.

Progression to manifest diabetes By the end of September 2003 (follow-up time 4-8 years, 1,677 subject years), 13 children had progressed to overt type 1 diabetes, five in the casein hydrolysate group (Table 1) and eight in the control group. One child in the control group (case 29) was diagnosed with type 1 diabetes at the age of 49 months, with 

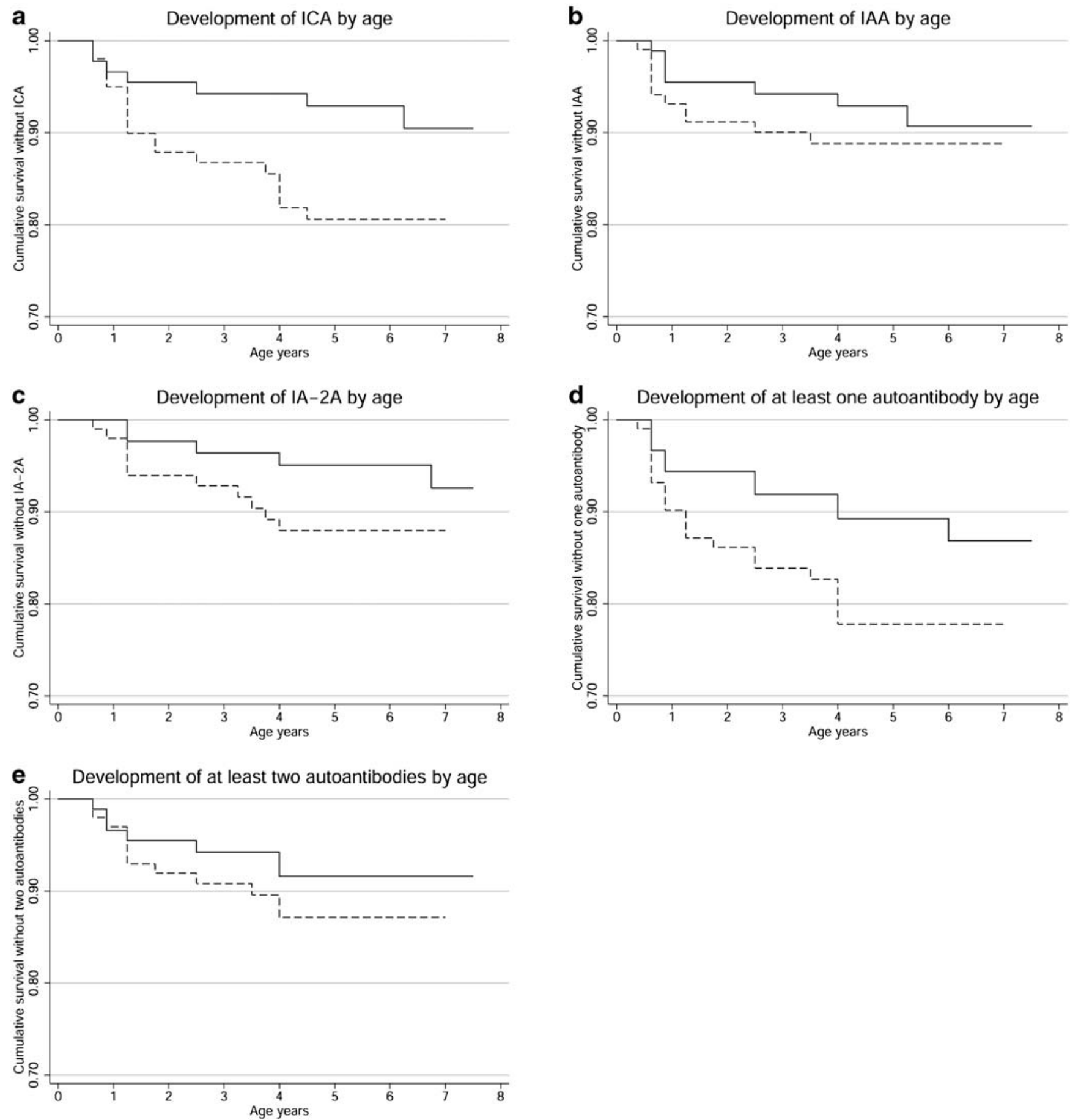

Fig. 1 Appearance of islet-cell antibodies (ICA) (a), insulin autoantibodies (IAA) (b), of anti-insulinoma-associated antigen-2 antibodies (IA-2A) (c) and of at least one (d) and at least two autoantibodies (e) by age in the casein hydrolysate (hydrolysed formula, solid line) group and in the control group (conventional

no detectable autoantibodies before the diagnosis. All the others tested positive for three or four autoantibodies before the diagnosis except one (case 12), who was positive for IAA only in her last sample taken at the age of 6 months, 14 months before the clinical presentation. One child in the casein hydrolysate group presented with diabetes at 10 months of age. This infant had left the study at the age

cow's milk-based formula, broken line) as survival curves in the Finnish study subjects $(n=208)$. Numbers of children in hydrolysate and control groups at 0 years, 91 and 101; at 1 year, 86 and 97; at 2 years, 82 and 94; at 3 years, 77 and 84 ; at 5 years, 71 and 72 ; and at 7 years, 38 and 34 , respectively

of 2 days on the mother's request. Another child in the casein hydrolysate group was withdrawn from the study at the age of 4 days and was diagnosed as having type 1 diabetes at the age of 5 years. These two children never received the study formula. Information of their diagnosis was obtained from the Finnish Social Insurance Registry. 
Table 2 Hazard ratios (HRs) for seroconversion to positivity of type 1 diabetes-associated antibodies according to study formula feeding in the Finnish children $(n=208)$

GADA Anti-glutamic acid decarboxylase antibodies, $I A-2 A$ anti-insulinoma-associated antigen-2 antibodies, IAA insulin autoantibodies, $I C A$ islet-cell antibodies
Diabetes-associated autoantibody (no. of seroconverters)

Hydrolysed casein vs cow's milk-based formula

Crude HR

(95\% CI)

$0.69(0.25-1.76), p=0.441$

$0.41(0.16-0.93), p=0.033$

$0.49(0.15-1.33), p=0.165$

$0.98(0.37-2.55), p=0.96$

$0.50(0.22-1.03), p=0.061$

0.64 (0.24-1.59), $p=0.336$
HR (95\% CI) adjusted for

duration of study formula feeding

$0.57(0.21-1.47), p=0.247$

$0.38(0.14-0.87), p=0.022$

$0.39(0.12-1.08), p=0.070$

0.87 (0.32-2.32), $p=0.781$

$0.44(0.20-0.93), p=0.032$

$0.53(0.19-1.34), p=0.182$

\section{Discussion}

Complex foreign proteins in the weaning diet have been discussed for decades as a candidate risk factor for type 1 diabetes. Experiments in BB rats [16] and NOD mice [17] have clearly demonstrated a deleterious effect of various complex foreign-protein weaning diets in the disease process. The strongest indirect evidence in man for an association between early exposure to dietary CM proteins and the risk of type 1 diabetes comes from epidemiological studies of infant feeding, with an inverse correlation between the duration of breastfeeding and the incidence of type 1 diabetes in childhood (reviewed in [1-3]). In our nationwide 'Childhood Diabetes in Finland' case-control series, the age at introduction of supplementary CM feeding was related to the risk of diabetes, independently of the duration of breastfeeding [18]. In a meta-analysis of the available case-control studies by 1993, Gerstein [19] observed that the overall odds ratio for the risk of type 1 diabetes in children exposed to a CM-based formula before the age of 3 months was 1.57 , while it was 1.37 in children having had a breastfeeding duration shorter than 3 months.

Other indirect evidence for the weaning risk hypothesis comes from ecological, epidemiological and immunological observations (reviewed in [1-3]). However, considerable criticism has been directed towards this hypothesis, and its possible mechanisms remain as obscure as the mechanisms that initiate and sustain progressive autoimmune islet destruction. If the risk association between the weaning diet and type 1 diabetes were to be substantiated in a sufficiently powered trial, it would point to important roles of the gut and the gut immune system, a possibility that has gained increasing attention in recent hypotheses on the pathogenesis of type 1 diabetes (reviewed in, e.g. [2, 20, 21]). With increasing age, both non-specific and specific immune defence mechanisms of the gut mature [21]. As a consequence, the permeability of the intestine to immunogenic proteins decreases, and the initial immune responses to $\mathrm{CM}$ proteins become weaker [9]. Dietary antigens associated with type 1 diabetes are accordingly more likely to affect the immune system in early infancy than later in childhood. These issues, as well as the question of the possible reduction in the number of cases with manifest type 1 diabetes after a dietary intervention in infancy, will be answered in the large, appropriately powered study-proper phase of TRIGR which is running in 15 countries from three continents. It should be stressed that at present there is no justification to change normal infant feeding practices.

The possible relationship between breastfeeding, weaning to an intact foreign-protein formula and the development of islet autoantibodies has been explored, but has generated inconsistent results. In the DAISY Study (Denver, CO, USA) of FDRs aged 0.7-7.1 years, neither age at initial exposure to $\mathrm{CM}$ nor breastfeeding duration was associated with risk of islet autoimmunity [22]. In a recent report from the German BABYDIAB study, surprisingly, the authors found that the life-table islet autoantibody risk was lowest in children who were never breastfed and highest in children exclusively breastfed for longer than 6 months [23]. The type of formula was, however, not considered in the analyses in either of these two studies. Weaning to hydrolysed formula is a common practice in the USA and Germany, whereas it is rare in Finland. In the population-based Finnish DIPP Study, in which newborn infants from the general population were recruited and those with risk HLA genotypes were observed in a nested case-control design, short breastfeeding and early introduction of CM-based formula predisposed these children to progressive signs of beta cell autoimmunity [5]. Such partly discrepant results may reflect true differences between different populations or may be due to substantial variations in infant feeding practices in various countries.

A core observation in the present pilot study was the reduced hazard ratios for seroconversion to positivity for ICA and for at least one autoantibody in the casein hydrolysate group, indicating that the early nutritional intervention may decrease the risk of emergence of beta cell autoimmunity to less than half of that in the control group (Fig. 1, Table 2). That we did not see a significantly decreased hazard ratio for other antibodies or subjects with multiple autoantibodies may be due to the limited statistical power of this pilot study. We wish to emphasise that a larger study is needed to confirm the borderline significances and non-significant trends in this pilot trial. Such a trial should also be carried out just to assess whether the intervention leads to a significant reduction in the frequency of each autoantibody reactivity analysed and of multiple autoantibodies.

Considering the increased interest in accelerated growth as a possible diabetogenic factor [24, 25], it was reassuring to note identical length/height and weight rates in the two study groups. As to other possible environmental exposures, there were no differences in the frequency of en- 
terovirus infections between the two groups [26]. The autoantibody data were derived from Finnish subjects only in this pilot study. Whether the present conclusions can be generalised to other populations will be assessed in the study proper, which comprises at least five countries with a considerable number of study subjects.

One important aspect of our pilot study was to evaluate the feasibility of a dietary intervention in infancy. We experienced a relatively high discontinuation rate mainly before the age of 3 months, i.e. before the first study team family contact after the delivery. In the current TRIGR international trial, we have increased the number of contacts with the families, especially over the initial 3 months, and we are observing smaller early drop-out rates. For the TRIGR trial, many changes have been made in written and oral family and personnel instructions derived from the experiences in the pilot study. The typing of $H L A-D Q B 1$ alleles from cord blood turned out to work efficiently in the pilot setting. Overall, we conclude that we gained invaluable experience from the pilot study, which we have had the opportunity to take into account in the design of the study proper.

We wish to emphasise that our study was a pilot trial and primarily a feasibility study. However, when considering the appearance of beta cell autoimmunity in the two groups, the trends of lower cumulative frequencies of antibody positivity in the casein hydrolysate group are a strong impetus for a larger study. Our observations exclude the possibility that a delayed exposure to $\mathrm{CM}$ proteins would increase the risk of autoantibody development. These data provide the first evidence ever in man that it may be possible to manipulate beta cell autoimmunity in a safe, practicable and ethically acceptable way, e.g. by dietary intervention in infancy. Indeed, this is the first indication that manipulation of the natural course of beta cell autoimmunity may be a realistic goal in man.

Acknowledgements We thank Prof. H.C. Gerstein and Prof. G. Dahlquist and Dr. J.A. VanderMeulen for collaboration and stimulating discussions in the planning stage of the TRIGR project, and Prof. D.J. Becker and Prof. J. Dupré for the same later in the project, and Prof. D.J. Becker and Prof. J.P. Krischer also for critical comments of the manuscript. We thank Prof. G.F. Bottazzo, Prof. G.J. Bruining, Prof. L. Madácsy and Prof. P. Pozzilli and Dr. M. Songini for their collaboration in the EU-sponsored part of the project. We thank Dr. J. W. Hansen and the Mead Johnson Nutritional Group for providing advice and study formulas. We are grateful to Ms. M. Salonen, Ms. T. Tenkula, Ms. A. Björk and Ms. K. Merentie for excellent work in the project office and with the study subjects. We thank Ms. S. Anttila, Ms. S. Heikkilä, Ms. S. Pohjola, Ms. R. Päkkilä and Ms. P. Salmijärvi for their skilful technical assistance in the autoantibody assays. In addition, we thank Mr. M. Koski for assistance in database work and Ms. S. Virkkunen and Ms. T. Terhonen for secretarial work. We deeply and foremost thank all the local study nurses and dietary advisors and participating families for effective collaboration. Grant support was from the Academy of Finland, the European Commission (BMH4CT96-0233), the Juvenile Diabetes Foundation International (File no. 195003), Helsinki University Central Hospital, the University of Helsinki, the Finnish Diabetes Research Foundation, the Novo Nordisk Foundation, the Medical Research Foundation of Tampere University Hospital, the Dorothea Olivia, Karl Walter and Jarl Walter Perklén Foundation, and the Liv och Hälsa Fund.

\section{Appendix}

The Finnish TRIGR Study Group. Principal investigator: H. K. Åkerblom. Local investigators: V. Eskola, H. Haavisto, A.-M. Hämäläinen, C. Holm, A.-L. Järvenpää, R. Jokisalo (retired), M.-L. Käär, U. Kaski (retired), J. Komulainen, P. Korpela, P. Lautala, K. Niemi, A. Nuuja, P. Rantanen, R. Renko, M. Renlund, M. Salo, T. Talvitie, T. Uotila and G. Wetterstrand. Special investigators: H. Hyöty, J. Ilonen, P. Klemetti, M. Knip, P.K. Kulmala, J. Paronen, A. Reunanen, T. Saukkonen, E. Savilahti, K. Savola, K. Teramo, O. Vaarala and S.M. Virtanen.

The Estonian TRIGR Study Group. National investigator: A. Ormisson. Local investigators: V. Astover, Ü. Einberg, Ü. Jakovlev, A. Kirss, R. Raukas and M.-A. Riikjärv.

The Swedish TRIGR Study Group. National investigator: J. Ludvigsson. Local investigators: I. Franzén, C. Granquist, U. Samuelsson and C. Törnquist.

\section{References}

1. Åkerblom HK, Knip M (1998) Putative environmental factors in type 1 diabetes. Diabetes Metab Rev 14:31-67

2. Harrison LC, Honeyman MC (1999) Cow's milk and type 1 diabetes: the real debate is about mucosal immune function. Diabetes 48:1501-1507

3. Naik RG, Palmer JP (1999) Preservation of beta-cell function in type 1 diabetes. Diabetes Rev 7:154-182

4. HummelM,Fuchtenbusch M, SchenkerM,Ziegler A-G(2000)No major association of breast-feeding, vaccinations, and childhood viral diseases with early islet autoimmunity in the German BABYDIABStudy.DiabetesCare 23:969-974

5. Kimpimäki T, Erkkola M, Korhonen S et al (2001) Short exclusive breast-feeding predisposes young children with increased genetic risk of type I diabetes mellitus to progressive beta-cell autoimmunity. Diabetologia 44:63-69

6. Åkerblom HK, Savilahti E, Saukkonen TT et al (1993) The case for elimination of cow's milk in early infancy in the prevention of type 1 diabetes: the Finnish experience. Diabetes Metab Rev 9:269-278

7. Karges W, Hammond-McKibben D, Cheung RK et al (1997) Immunological aspects of nutritional diabetes prevention in NOD mice: a pilot study for the cow's milk-based IDDM prevention trial. Diabetes 46:557-564

8. Malkani S, Nompleggi D, Hansen JW, Greiner DL, Mordes JP, Rossini AA (1997) Dietary cow's milk protein does not alter the frequency of diabetes in the BB rat. Diabetes 46:1133-1140

9. Vaarala O, Saukkonen T, Savilahti E, Klemola T, Åkerblom HK (1995) Development of immune response to cow's milk proteins in infants receiving cow's milk or hydrolyzed formula. J Allergy Clin Immunol 96:917-923

10. Ilonen J, Reijonen H, Herva E et al (1996) Rapid HLA-DQB1 genotyping for four alleles in the assessment of risk for IDDM in the Finnish population. Diabetes Care 19:795-800

11. Sjöroos M, Iitiä A, Ilonen J, Reijonen H, Lövgren T (1995) Triple-label hybridization assay for type-1 diabetes-related HLA alleles. BioTechniques 18:870-877

12. Kukko M, Virtanen SM, Toivonen A et al (2004) Geographical variation in risk HLA-DQB1 genotypes for type 1 diabetes and signs of $\beta$-cell autoimmunity in a high-incidence country. Diabetes Care 27:676-681 
13. Lernmark A, Molenaar JL, van Beers WA et al (1991) The fourth international serum exchange workshop to standardize cytoplasmic islet cell antibodies. The immunology and diabetes workshops and participating laboratories. Diabetologia 34:534535

14. Reunanen A, Kangas T, Martikainen J, Klaukka T (2000) Nationwide survey of comorbidity, use, and costs of all medications in Finnish diabetic individuals. Diabetes Care 23:1265-1271

15. Prentice RL, Gloeckler LA (1978) Regression analysis of grouped survival data with application to breast cancer data. Biometrics 34:57-67

16. Elliott RB, Martin JM (1984) Dietary protein: a trigger of insulin-dependent diabetes in the BB rat? Diabetologia 26:297299

17. Elliott RB, Reddy SN, Bibby NJ, Kida K (1988) Dietary prevention of diabetes in the non-obese diabetic mouse. Diabetologia 31:62-64

18. Virtanen SM, Räsänen L, Ylönen K et al (1993) Early introduction of dairy products associated with increased risk of IDDM in Finnish children. Diabetes 42:1786-1790

19. Gerstein HC (1994) Cow's milk exposure and type I diabetes mellitus. A critical overview of the clinical literature. Diabetes Care 17:13-19
20. Kolb H, Pozzilli P (1999) Cow's milk and type I diabetes: the gut immune system deserves attention. Immunol Today 20: $108-110$

21. Vaarala O (1999) Gut and the induction of immune tolerance in type 1 diabetes. Diabetes Metab Res Rev 15:353-361

22. Norris JM, Barriga K, Klingensmith G et al (2003) Timing of initial cereal exposure in infancy and risk of islet autoimmunity. JAMA 290:1713-1720

23. Ziegler A-G, Schmid S, Huber D, Hummel M, Bonifacio E (2003) Early infant feeding and risk of developing type 1 diabetes-associated autoantibodies. JAMA 290:1721-1728

24. Wilkin TJ (2001) The accelerator hypothesis: weight gain as the missing link between type I and type II diabetes. Diabetologia 44:914-922

25. Åkerblom HK, Vaarala O, Hyöty H, Ilonen J, Knip M (2002) Environmental factors in the etiology of type 1 diabetes. Am J Med Genet 115:18-29

26. Sadeharju K, Hämäläinen AM, Knip M et al (2003) Enterovirus infections as a risk factor for type 1 diabetes: virus analyses in a dietary intervention trial. Clin Exp Immunol 132:271-277 